\title{
Multiscreening LC-MS/MS Designed for Ten Pesticide and Six Antimicrobial Residues in Eggs
}

\author{
Julia Arantes Galvão, ${ }^{1}$ Ricardo Seiti Yamatogi, ${ }^{1}$ Alexander Welker Biondo, ${ }^{2}$ \\ José Paes de Almeida Nogueira Pinto, ${ }^{1}$ José Roberto Marques Silva, ${ }^{3}$ \\ Caio Antonio Carbonari, ${ }^{3}$ and Edivaldo Domingues Velini ${ }^{3}$ \\ ${ }^{1}$ Department of Veterinary Hygiene and Public Health, School of Veterinary Medicine and Animal Science, \\ Univ. Estadual Paulista (UNESP), Distrito de Rubião Júnior, s/n, 18618-970 Botucatu, SP, Brazil \\ ${ }^{2}$ Department of Veterinary Medicine, Federal University of Parana, 80035-050 Curitiba, PR, Brazil \\ ${ }^{3}$ Center for Advanced Research in Matology (CARM), Chromatography Laboratory, Faculty of Agricultural Sciences, \\ Paulista State University, 18618-970 Botucatu, SP, Brazil
}

Correspondence should be addressed to Julia Arantes Galvão; juliaarantesgalvao@gmail.com

Received 28 July 2016; Accepted 6 December 2016; Published 22 January 2017

Academic Editor: Ángel A. Carbonell-Barrachina

Copyright (c) 2017 Julia Arantes Galvão et al. This is an open access article distributed under the Creative Commons Attribution License, which permits unrestricted use, distribution, and reproduction in any medium, provided the original work is properly cited.

A multiscreening method was experimentally validated for pesticide and antimicrobial residues in spiked eggs at levels of 5, 50, and $500 \mu \mathrm{g} \mathrm{L}^{-1}$. The residue extraction was performed with acetonitrile and $1 \%$ formic acid. The extracted material was stored at $-70^{\circ} \mathrm{C}$ until detection and quantitation within 24-hour period by LC-MS/MS. Pesticide and antimicrobial residue recovery performed adequate standard deviation and the results were from $94.10 \%$ (ampa) to $9.20 \%$ (carbaryl) for pesticides and from $95.70 \%$ (enrofloxacin) to $46.20 \%$ (sulfathiazole) for antimicrobial. The method was highly accurate, considering the linearity for all pesticide and antimicrobial residues $\left(r^{2}>0.99\right)$, with quantitation limits ranging from 0.78 to $6.25 \mu \mathrm{g} \mathrm{L}{ }^{-1}$ for pesticides and 0.78 to $3.13 \mu \mathrm{g} \mathrm{L}{ }^{-1}$ for antibiotics. A highly correlation coefficient $(r>0.99)$ was found, except for carbaryl. Although time extraction and carbaryl recovery remain to be improved, the method has shown a rapid pesticide and antimicrobial residue detection.

\section{Introduction}

Although pesticides have been the main global tool for weed, pest, and disease in agricultural control, detection methods of pesticide residues in animal products remain antiquated compared to agricultural and environmental methodologies [1]. In recent years, Brazilian agriculture has experienced exponential growth, as well as the country becoming the world's top consumer of pesticides $[2,3]$.

Eggs have been considered an inexpensive and nutritive food source with worldwide production of 68,262 thousand tons in 2013 [4], with antimicrobial residues in food security having been uncertain in developing countries, but detection methodology established and routinely used [5-8].

Whereas European Union has listed veterinary drug presence in two alert notifications (trimethoprim, sulfonamide, enrofloxacin, and toltrazuril) between January, 2013, and
September, 2016, in eggs and egg products, no pesticide notification has been made during this period [9]. Moreover, no specific regulation has been globally provided for egg and egg products, although maximum levels of pesticide and antibiotic residues in food were established worldwide $[10,11]$.

Since Brazil has been also listed as the seventh world biggest egg producer [12], a rapid, simple, and reliable multiresidue detection would provide current sanitary status, food control, and prevention. Accordingly, the aim of the present study was to validate a multiscreening method based on LC-MS/MS for ten pesticide and six antimicrobial residues in egg contents.

\section{Material and Methods}

2.1. Egg Samples. Egg samples were provided by two highproduction egg farms certified by the Brazilian Inspection 
Service in Sao Paulo State, Brazil: Farm A with both conventional and free-range systems and Farm B with conventional system. There were 10 eggs from each system, totaling 30 eggs. These samples were stored at under frost conditions $\left(-20^{\circ} \mathrm{C}\right)$ in a Falcon tube until analysis.

2.2. Equipment and Residues. Analyses were carried out by a LC-MS/MS system, composed by commercially available High Performance Liquid Chromatograph (Proeminence UFLC, Shimadzu Co., Sao Paulo, Brazil) coupled to a mass spectrometer (3200QTRAP, Applied Biosystems, Sao Paulo, Brazil). The triple quadrupole analysis mode, which is Q3 only defined to detect one especial mass and known fragment from the intact molecule of identified mass filtered by Q1, was selected and used $[13,14]$.

Pesticide residues of aminomethylphosphonic acid (ampa), epoxiconazole, fipronil, metolachlor, malathion, flutriafol, pyraclostrobin, carbendazim, glyphosate, and carbaryl, complying with the maximum residue limits (MRL) established by Codex Alimentarius for soy and corn grains [15], were selected and tested. These residues represented the most common pesticides applied in corn and soy crops, the worldwide main ingredients for laying hen feeding.

Antimicrobials residues of enrofloxacin, sulfamethazine, sulfadimethoxine, sulfadiazine, chloramphenicol, and sulfathiazole, complying with the maximum residue limits (MRL) established for eggs [15], were selected and tested. In addition, comparisons were made with a previous study of drug use in poultry in Paraná State [18] and worldwide $[19,20]$.

\subsection{Validation of Liquid Chromatography Analysis and Mass} Spectrometry. To validate the methodology, several experimental studies for analytical curve linearity, limit of detection and quantitation, precision (repeatability, and intermediate precision), and accuracy $[21,22]$ were considered.

To optimize mass spectrometry conditions, direct injections to the equipment were performed with standard analytical solution of $1 \mathrm{mg} \mathrm{L}^{-1}$ from each compound, individually. The analytical standards for tests were commercially acquired with $98 \%$ purity or higher (Sigma-Aldrich, Sao Paulo, Brazil). From infusions, ESI (electrospray ionization) was picked as the ionization source, which produces analyte ions on liquid phase prior to entering mass spectrometer. Negative ionization mode was utilized to glyphosate and ampa. For other compounds, positive ionization was done.

Chromatographic conditions used for compound quantifications on negative ionization mode were a chromatographic column (Gemini 5 micrometers C18 $110 \AA 150 \mathrm{~mm} \times$ $4.6 \mathrm{~mm}$ ) with phase $\mathrm{A}(\mathrm{PA})=5 \mathrm{mM}$ of ammonium acetate in water and phase $\mathrm{B}(\mathrm{PB})=5 \mathrm{mM}$ of ammonium acetate in methanol on mobile phase, $0-4 \mathrm{~min}=10 \% \mathrm{~PB}$ and $90 \%$ $\mathrm{PA} ; 4-6 \mathrm{~min}=95 \% \mathrm{~PB}$ and $5 \% \mathrm{PA} ; 6-8 \mathrm{~min}=95 \% \mathrm{~PB}$ and $5 \% \mathrm{PA} ; 8-10 \mathrm{~min}=10 \% \mathrm{~PB}$ and $90 \% \mathrm{PA}$ with $12 \mathrm{~min}$ stop on mobile phase gradient and on mobile phase flow rate $0.500 \mathrm{~mL} \mathrm{~min}^{-1}$.

Chromatographic conditions used for compound quantifications on positive ionization mode were a chromatographic column (Synergi 2.5 micrometers Hydro-RP $110 \AA 50$ $\times 4.60 \mathrm{~mm})$ with phase $\mathrm{A}(\mathrm{PA})=0.1 \%$ formic acid in water and phase $\mathrm{B}(\mathrm{PB})=0.1 \%$ formic acid in methanol on mobile phase, $0-0.5 \mathrm{~min}=10 \% \mathrm{~PB}$ and $90 \% \mathrm{PA} ; 0.5-4.5 \mathrm{~min}=95 \%$ $\mathrm{PB}$ and 5\% FA; 4.5-7.5 $\mathrm{min}=95 \% \mathrm{~PB}$ and 5\% PA; 7.5-9.5 $\mathrm{min}$ $=10 \% \mathrm{~PB}$ and $90 \% \mathrm{PA}$ with $11 \mathrm{~min}$ stop on mobile phase gradient and on mobile phase flow rate $0.400 \mathrm{~mL} \mathrm{~min}^{-1}$.

Monitoring more than one ion was necessary to avoid erroneous identifications of the composing quantification. LC-MS/MS use enabled control of molecular ion and ionic transition from substance fragmentation, ensuring sensitivity and specificity for an accurate measurement of weak traces of analytes, sometimes present in highly complex matrices $[13,14]$.

2.4. Analytical Curve. The analytical curve is the quantification tool most commonly used. It consists in determining response of any particular instrument to various concentrations of a tested substance. Commonly chromatographic analytical techniques use a first-order linear association between detector response $(y)$ and concentration $(x)$ of the analyte $[23,24]$. This mathematical relation must also have a high correlation coefficient $(r>0.9999)$ and may be represented by the linear regression equation described below [25]:

$$
y=a x+b,
$$

where $b$ is the intersection of the calibration curve and $a$ is the slope.

2.5. Residue Extraction. The congealed egg content samples were defrosted into a refrigerator for 24 hours. Then, $2.50 \mathrm{~g}$ of homogenate albumen and yolk were weighted and homogenized into a Falcon tube with $5 \mathrm{~mL}$ of ultrapure water by Turrax. After, $15 \mathrm{~mL}$ of acetonitrile containing $1 \%$ formic acid was aggregated, generating a 20 -fold dilution of the sample. Diluted sample was maintained under continuous and intense stirring for one hour. The tube was centrifuged (10 min/2000 rcf) (Rotanta 460R), and $0.50 \mathrm{~mL}$ of the supernatant was sifted through $0.45 \mu \mathrm{M}$ Millex $\mathrm{HV}$ filters (Millipore), with a $13 \mathrm{~mm}$ durapore membrane, and packaged in a $9 \mathrm{~mm}$ amber vial (Flow Supply), for subsequent quantification by LC-MS/MS (Mol et al. 2008 adapted).

For checking the recovery, a sample enrichment was performed by a sample solution containing a mixture of the analytical standards representing itself contents of 5, 50, and $500 \mu \mathrm{g} \mathrm{L}^{-1}$ from each compound. Four replications were performed. The average recovery and standard deviation were calculated by matching enriched samples versus calibration matrix standards. Recovery outcome reflected on the recuperation of extraction process. Results were calculated by comparing response obtained from each component with the matching matrix pattern.

\section{Results and Discussion}

3.1. Validation of Liquid Chromatography Analysis and Mass Spectrometry. The molecular mass and fragments produced from each pesticide molecule, respectively, were ampa 109.99 (62.90, 78.90, and 80.80), epoxiconazole 330.15 (121.00, 101.10, and 75.10) fipronil 436.91 (368.00, 251.10, and 263.10), 
metolachlor 284.21 (252.30, 176.20, and 91.10), malathion 331.01 (99.00, 127.10, and 125.00), flutriafol 302.10 (70.00, $123.20,95.00)$, pyraclostrobin $388.13(163.20,194.30$, and $104.20)$, carbendazim $192.25(160.20,132.30$, and 105.10), glyphosate 167.92 (63.10, 78.80, and 150.20), and carbaryl 202.15 (145.10, 127.10, and 117.20), and, for each antimicrobials, respectively, were enrofloxacin $360.23(342.30,245.30$, and 203.20), sulfamethazine $279.01(108.20,92.20$, and 156.30), sulfadimethoxine $311.01(155.90,108.20$, and 64.90$)$, sulfadiazine 250.87 (156.20, 64.90, and 108.20), chloramphenicol $322.84(275.00,165.10$, and 83.20), and sulfathiazole 256.04 $(92.10,156.10,65.20)$

The detection and separation of the substances were performed in two intervals, a negative mode (12 minutes) and a positive mode (11 minutes). The retention time for each compound in the chromatographic column was $3.65 \mathrm{~min}$ for ampa, $6.65 \mathrm{~min}$ for epoxiconazole, $6.53 \mathrm{~min}$ for fipronil, $6.76 \mathrm{~min}$ for metolachlor, $6.46 \mathrm{~min}$ for malathion, $6.04 \mathrm{~min}$ for flutriafol, $6.86 \mathrm{~min}$ for pyraclostrobin, $3.98 \mathrm{~min}$ for carbendazim, $4.02 \mathrm{~min}$ for glyphosate, $5.95 \mathrm{~min}$ for carbaryl, $4.20 \mathrm{~min}$ for enrofloxacin, $4.50 \mathrm{~min}$ for sulfamethazine, $5.24 \mathrm{~min}$ for sulfadimethoxine, $3.97 \mathrm{~min}$ for sulfadiazine, $5.35 \mathrm{~min}$ for chloramphenicol, and $4.03 \mathrm{~min}$ for sulfathiazole. There is an example of analytical standard chromatogram $\left(6.25 \mu \mathrm{g} \mathrm{L}^{-1}\right)$ of sulfadimethoxine under conditions described (Figure 1).

3.2. Analytical Curve. The analytical curves were constructed for compounds resulting in $r^{2}$ and linear interval, respectively: ampa (0.98 and $\left.1.56-200 \mu \mathrm{L}^{-1}\right)$; epoxiconazole $(0.99$ and $\left.0.78-200 \mu \mathrm{L}^{-1}\right)$; fipronil (0.99 and 0.78-100); metolachlor (0.99 and 0.78-100); malathion (0.99 and 0.78-200); flutriafol (0.99 and 0.78-200); pyraclostrobin (0.99 and 0.78$100)$; carbendazim (0.98 and $0.78-100)$; glyphosate ( 0.99 and $0.78-200)$; carbaryl (0.98 and 0.78-100); enrofloxacin (0.98 and 1.56-200); sulfamethazine (0.99 and 0.78-200); sulfadimethoxine (0.98 and $0.78-200)$; sulfadiazine ( 0.99 and $0.78-$ $100)$; chloramphenicol (0.99 and 3.13-200); and sulfathiazole (0.99 and 1.56-100). The linear model used in the equations model showed to be very suitable $[21,22,25]$.

3.3. Residue Extraction. The average concentration recovery for studied pesticides was 5.62 to $99.40 \%$ and for antimicrobial 63.80 to $100 \%$, except for sulfathiazole, with $49.00 \%$ (Table 1). Since minimum limit of quantification (MLQ) is of 1.56 of sulfathiazole, it is possible to qualify the residue recovery by MRL $\left(10 \mu \mathrm{g} \mathrm{L}^{-1}\right)$ hypothetic extrapolation accepted by the Ministry of Agriculture (Brasil, 2013). So, although the lower range of recovery, there is linearity on results.

Minimum limits of quantification (MLQ) were 0.78 to $6.25 \mu \mathrm{g} \mathrm{L}^{-1}$ for pesticides and 0.78 to $3.13 \mu \mathrm{g} \mathrm{L}^{-1}$ for antimicrobials. This complies the needs for residue screening, considering MRL established by national and international legislation [10,15], except for chloramphenicol, whose MRL is $0.30 \mu \mathrm{g} \mathrm{L}^{-1}[10]$, and its MLQ was $3.13 \mu \mathrm{g} \mathrm{L}^{-1}$.

For pesticides, average recovery was more variable, although linearity has also been observed in all the compound recuperation. Average recovery of ampa, epoxiconazole, fipronil, and metolachlor was considered excellent (56.17

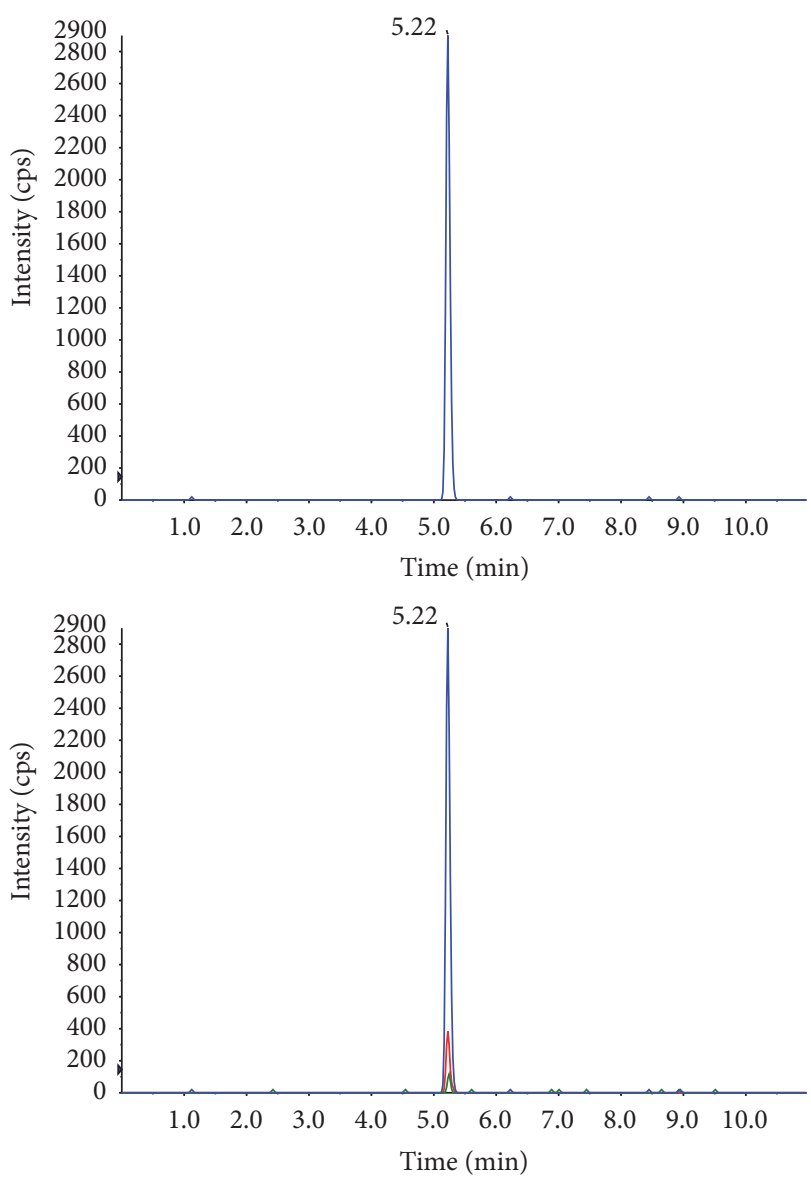

FIgURE 1: Chromatograms of sulfadimethoxine and fragments generated at concentration of $6.25 \mu \mathrm{g} \mathrm{L}^{-1}$, Botucatu/SP, 2013.

to $94.08 \%)$. Analyzed substances in the medium recovery range from 24.17 to $48.05 \%$ were considered of moderate efficiency (malathion, flutriafol, pyraclostrobin, and cabendazim). Low average recovery was observed for glyphosate and carbaryl (19.23 and 9.20\%, resp.). None of these compounds has MRL established for egg, only for corn and soybeans [15].

On considering the minimum quantitation limits, high correlation coefficient $(r>0.99)$, and the large number of evaluated compounds, this residue extraction method through acetonitrile, with added $1 \%$ formic acid, was considered efficient for quantifying all compounds assessed in this study, except for carbaryl. In this case, an alternative extraction method should be performed. In summary, even touch time extraction and carbaryl recovery persist to be enhanced, and this multiscreening method for egg residues has shown a rapid pesticide and antimicrobial residue detection.

\section{Additional Points}

Practical Applications. We described the validation of a LC-MS/MS method to simultaneous determination of ten pesticides and six antimicrobial. The methodology may be applied in laboratory routine. 


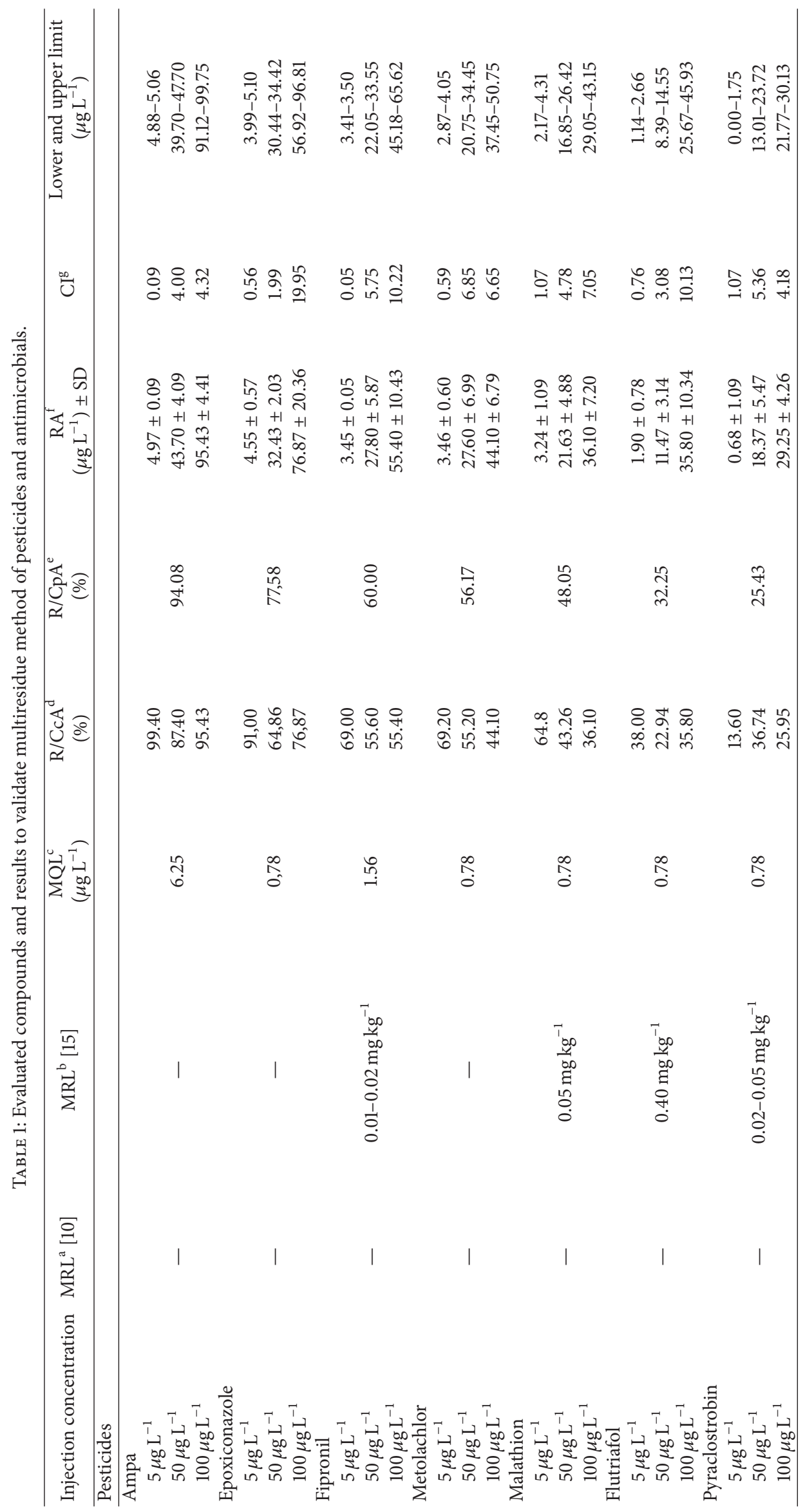




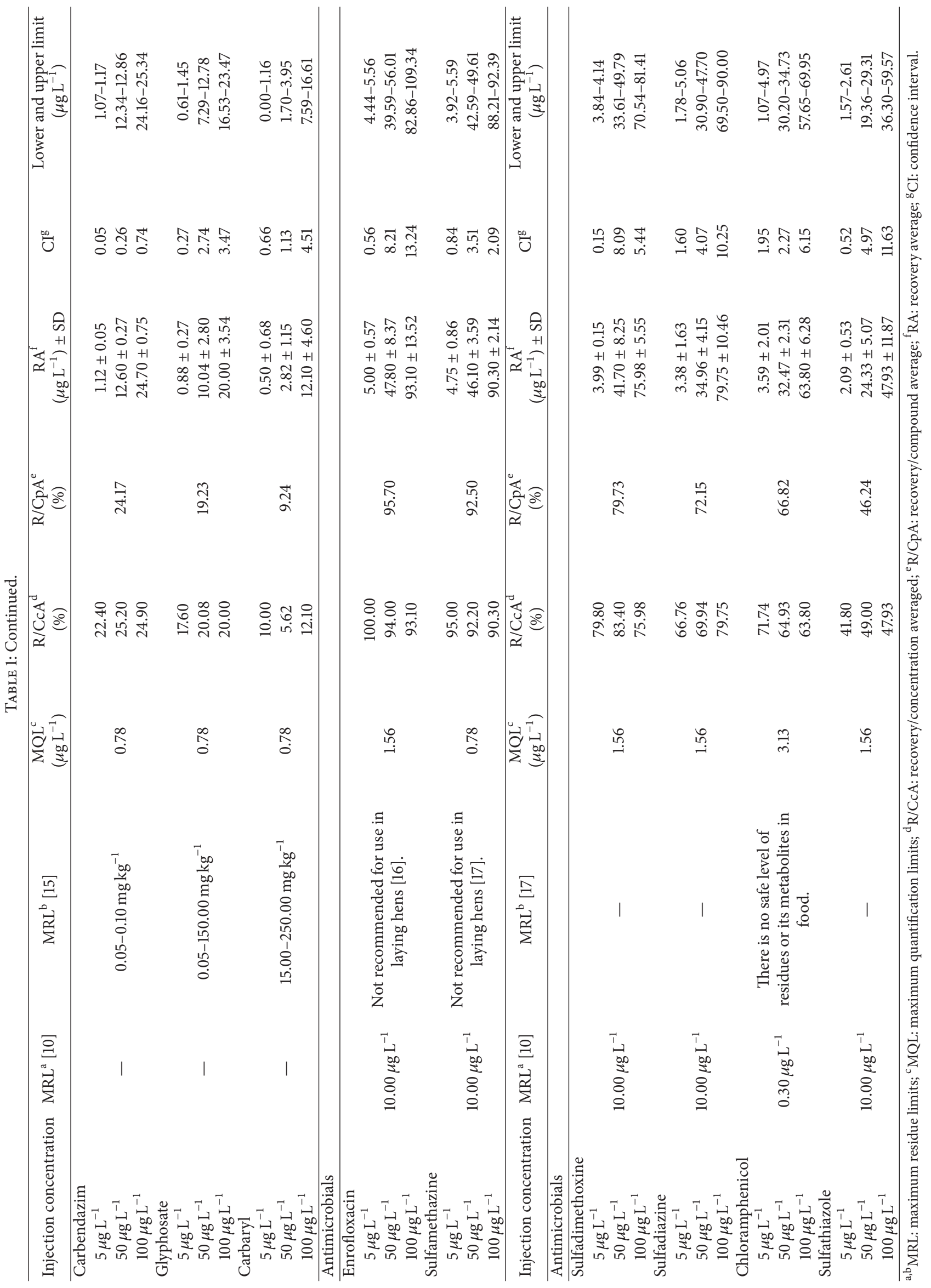




\section{Disclosure}

Julia Arantes Galvão is currently at Department of Veterinary Medicine, Federal University of Parana, 80035-050 Curitiba, PR, Brazil.

\section{Competing Interests}

The authors declare that they have no competing interests.

\section{References}

[1] M. LeDoux, "Analytical methods applied to the determination of pesticide residues in foods of animal origin. A review of the past two decades," Journal of Chromatography A, vol. 1218, no. 8, pp. 1021-1036, 2011.

[2] Agência Nacional de Vigilância Sanitária (ANVISA), Seminário volta a discutir mercado de agrotóxicos em 2012, 2012, http:// portal.anvisa.gov.br/.

[3] I. B. Geografia and E. De Estatística, Indicadores de desenvolvimento sustentável: Brasil: 2015/IBGE, Coordenação de Recursos Naturais e Estudos Ambientais, Estudos e Pesquisas. Informação Geográfica No. 10, Coordenação de Geografia, Rio de Janeiro, Brazil, 2015.

[4] STATISTA, Global egg production from 1990 to 2013, https:// www.statista.com/statistics/263972/egg-production-worldwidesince-1990/.

[5] W. A. Moats, "Inactivation of antibiotics by heating in foods and other substrates-a review," Journal of Food Protection, vol. 51, no. 6, pp. 491-497, 1988.

[6] Y. Xu, J. Ding, H. Chen et al., "Fast determination of sulfonamides from egg samples using magnetic multiwalled carbon nanotubes as adsorbents followed by liquid chromatographytandem mass spectrometry," Food Chemistry, vol. 140, no. 1-2, pp. 83-90, 2013.

[7] N. Bilandžić, Đ. Božić, B. S. Kolanović, I. Varenina, L. Cvetnić, and Ž. Cvetnić, "Distribution of sulfamonomethoxine and trimethoprim in egg yolk and white," Food Chemistry, vol. 178, pp. 32-37, 2015.

[8] S. Moscoso, F. S. De Los Santos, A. G. Andino, S. Diaz-Sanchez, and I. Hanning, "Detection of quinolones in commercial eggs obtained from farms in the Espaíllat Province in the Dominican Republic," Journal of Food Protection, vol. 78, no. 1, pp. 214-217, 2015.

[9] European Commission, RASFF-Food and Feed Safety Alerts-European Commission, 2016, https://webgate.ec.europa.eu/rasff-window/portal/.

[10] Ministry of Agriculture, Livestock, and Food Supply, "Monitoring subprogram and exploratory subprogram of the national plan for the control of residues and contaminants-PNCRC of 2015," Normative Instruction 13, Ministry of Agriculture, Livestock and Food Supply, Brasilia, Brazil, 2015.

[11] European Commission, "Commission Regulation (EU) No $37 / 2010$ of 22 December 2009 on pharmacologically active substances and their classification regarding maximum residue limits in foodstuffs of animal origin," Official Journal of the European Union, vol. L 15/1, 2010.

[12] FAO. Food and Agriculture Organization of the United Nations, FAO Statistical Pocketbook, Food and Agriculture Organization of the United Nations, Rome, Italy, 2015.
[13] C. L. Queiroga, Analisadores de massa: QTRAP, Espectrometria de Massas: Princípios E Aplicações, 2010, http://www.espectrometriademassas.com.br.

[14] S. K. G. Grebe and R. J. Singh, "LC-MS/MS in the clinical laboratory-where to from here?" Clinical Biochemist Reviews, vol. 32, no. 1, pp. 5-31, 2011.

[15] FAO/WHO. Food and Agriculture Organization of the United Nations, WHO. World Health Organization, Food Standards, Codex Alimentarius: pesticide residues in food and feed, 2013.

[16] EMEA, The European Agency for the Evaluation of Medicinal Products Veterinary Medicines and Inspections, Committee for Veterinary Medicinal Products, Enrofloxacin, EMEA/MRL/ 820/02-FINAL, 2002.

[17] FAO/WHO_Food and Agriculture Organization of the United Nations. WHO. World Health Organization, International Food Standards, Codex Alimentarius: Maximum Residue Limits (MRLs) and Risk Management Recommendations (RMRs) for residues of veterinary drugs in foods, 2015.

[18] M. Machinski Jr., A. Benini, D. P. Neto et al., Medicamentos veterinários utilizados na avicultura de postura no estado do Paraná, Curitiba: Programa Estadual de Controle de Resíduos de Medicamentos Veterinários em Alimentos de Origem Animal, PAMvet-PR, 2005.

[19] V. Goetting, K. A. Lee, and L. A. Tell, "Pharmacokinetics of veterinary drugs in laying hens and residues in eggs: a review of the literature," Journal of Veterinary Pharmacology and Therapeutics, vol. 34, no. 6, pp. 521-556, 2011.

[20] T. Marmulak, L. A. Tell, R. Gehring, R. E. Baynes, T. W. Vickroy, and J. E. Riviere, "Egg residue considerations during the treatment of backyard poultry," Journal of the American Veterinary Medical Association, vol. 247, no. 12, pp. 1388-1395, 2015.

[21] M. Ribani, C. H. Collins, and C. B. G. Bottoli, "Validation of chromatographic methods: evaluation of detection and quantification limits in the determination of impurities in omeprazole," Journal of Chromatography A, vol. 1156, no. 1-2, pp. 201205, 2007.

[22] SANCO, "Guidance document on analytical quality control and validation procedures for pesticide residues analysis in food and feed," Document SANCO/12571/2013, Health \& Consumer Protection Directorate-General, Brussels, Belgium, 2013.

[23] M. Feinberg, "Validation of analytical methods based on accuracy profiles," Journal of Chromatography A, vol. 1158, no. 1-2, pp. 174-183, 2007.

[24] G. A. Shabir, "Validation of high-performance liquid chromatography methods for pharmaceutical analysis: understanding the differences and similarities between validation requirements of the US Food and Drug Administration, the US Pharmacopeia and the International Conference on Harmonization," Journal of Chromatography A, vol. 987, no. 1-2, pp. 57-66, 2003.

[25] FAO/ISRIC-Food and Agriculture Organization of the United Nations. ISRIC-International Soil Reference and Information Centre, Guidelines for Quality Management in Soil and Plant Laboratories, (FAO Soils Bulletin-74). 7 Quality of Analytical Procedures, 1998. 

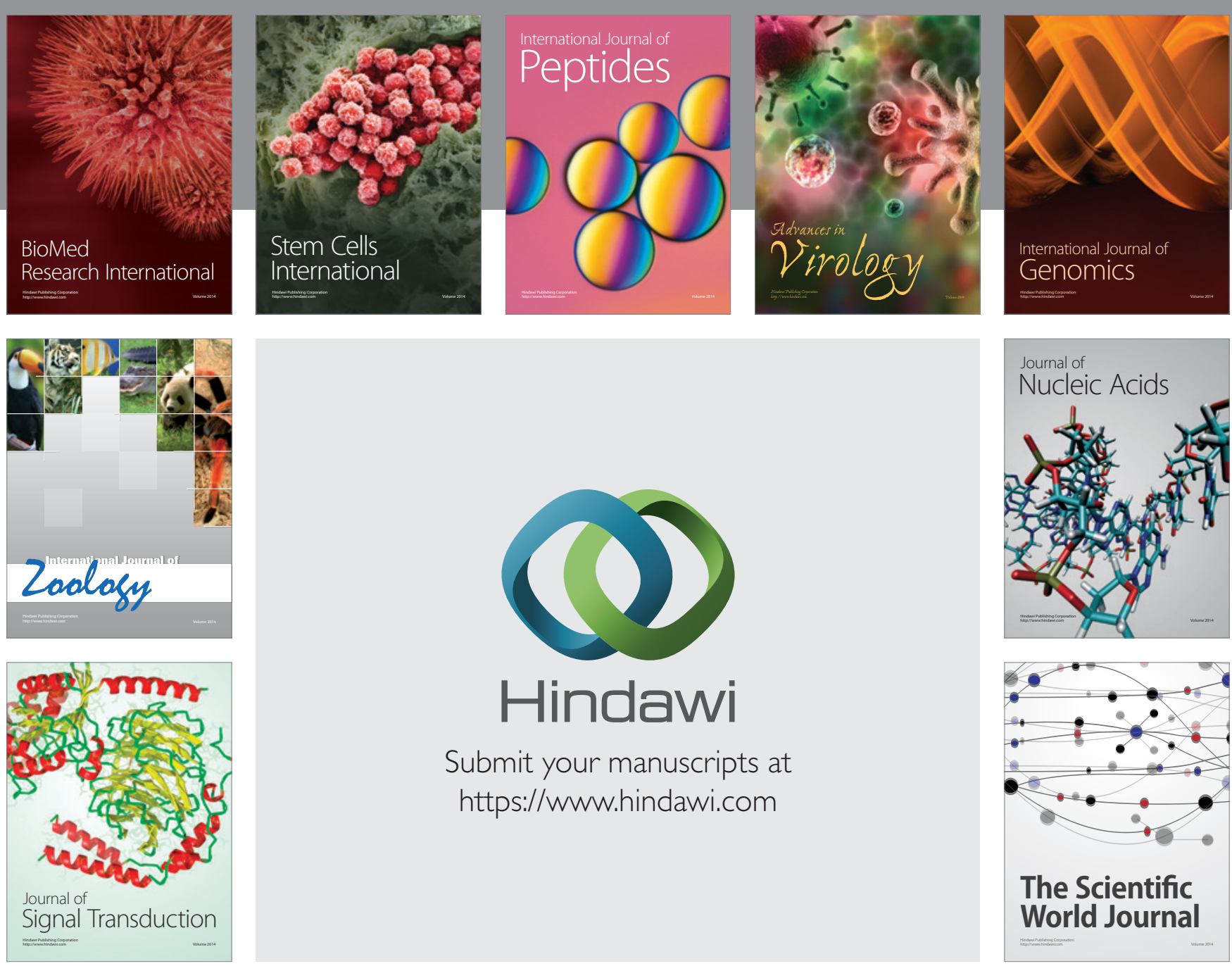

Submit your manuscripts at

https://www.hindawi.com
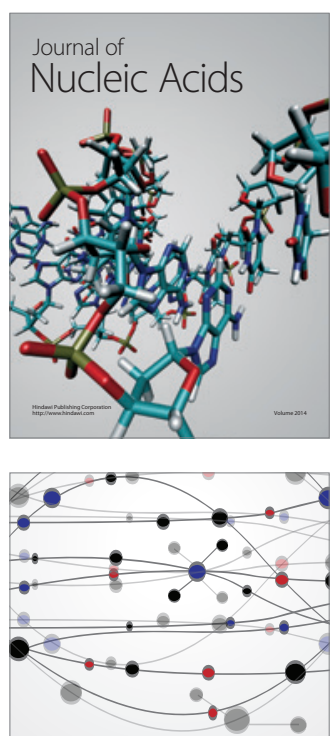

The Scientific World Journal
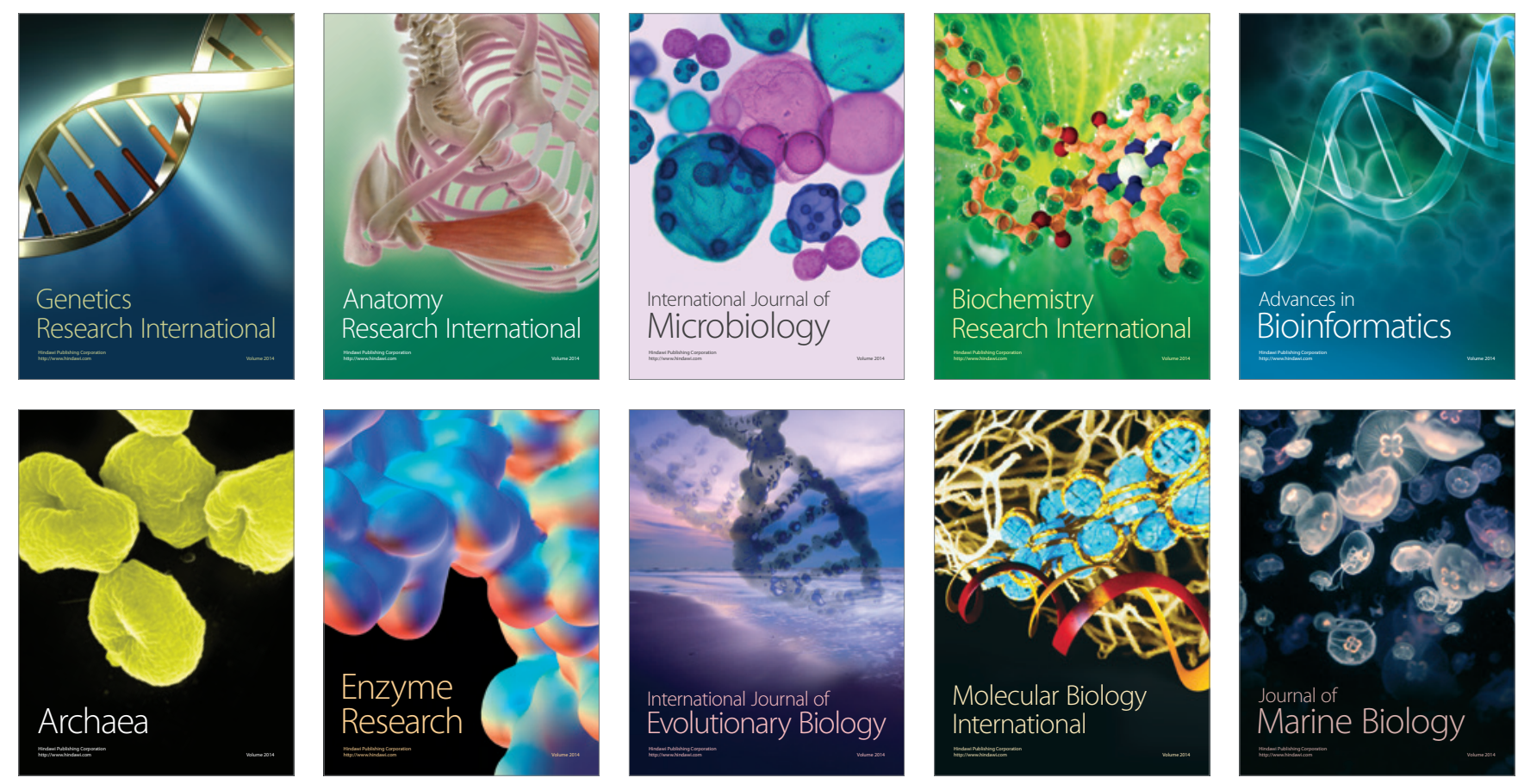